\title{
Prevalence of Diabetes Mellitus among Adult Residents of Tinda Rural Community, Nigeria
}

\author{
Temitope D. Afolalu1, Ojima Z. Wada ${ }^{2 *}$, David B. Olawade², Audi D. Suntai ${ }^{3}$ \\ ${ }^{1}$ Department of Nursing Science, Afe Babalola University, Ado-Ekiti, Nigeria \\ ${ }^{2}$ Department of Environmental Health Sciences, University of Ibadan, Ibadan, Nigeria \\ ${ }^{3}$ Department of Medicine, Universad Nacional Experimental de los Llanos Centrales Romulo Gallegos, Zaraza, Venezuela \\ Email: *ojimawada14@gmail.com
}

How to cite this paper: Afolalu, T.D., Wada, O.Z., Olawade, D.B. and Suntai, A.D. (2020) Prevalence of Diabetes Mellitus among Adult Residents of Tinda Rural Community, Nigeria. Journal of Biosciences and $\mathrm{Me}$ dicines, 8, 107-116.

https://doi.org/10.4236/jbm.2020.811010

Received: October 3, 2020

Accepted: November 13, 2020

Published: November 16, 2020

Copyright (C) 2020 by author(s) and Scientific Research Publishing Inc. This work is licensed under the Creative Commons Attribution International License (CC BY 4.0).

http://creativecommons.org/licenses/by/4.0/

\section{Open Access}

\begin{abstract}
Aim: Diabetes mellitus (DM) is an emerging disease of public health concern in Nigeria. There has been growing speculation about rural dwellers not being susceptible to this ailment due to their lifestyle. However, this could be attributed to the paucity of data obtained from rural communities. This community-based survey was conducted to provide recent data about the prevalence of DM in a rural community in Northern Nigeria. Subject and Methods: Purposive sampling was used to recruit 78 participants from about 200 adults within the community in September 2019. Consent was obtained to retrieve their blood glucose results and socio-demographic data from an out-patient clinic. Data were entered and analyzed using SPSS version 20. Results: Over half $(55 \%)$ of the respondents were male, while majority ( $88 \%)$ were involved in agrarian professions. Majority (69\%) of the respondents were between 18 to 35 years, while around $10 \%$ were over 50 years. The respondents had an average blood glucose level of $5.20 \pm 0.62 \mathrm{mmol} / \mathrm{L}$, with $6.50 \mathrm{mmol} / \mathrm{L}$ as the maximum reading. The prevalence of DM was $0.0 \%$, majority $(68 \%)$ had normal glucose level, while the remainder had pre-diabetes glucose levels. There were no statistically significant associations between the respondents' blood glucose level and any of their socio-demographic characteristics. However, the oldest respondents, male respondents, and traders had the highest blood glucose levels in their respective categories. Conclusion: The absence of a healthcare center in the community was of concern, as this would impede efforts to monitor the prevalence of non-communicable disease like DM. It is recommended that health interventions to discourage the rural dwellers from embracing adverse urban lifestyles associated with DM should be prioritized.
\end{abstract}

\section{Keywords}

Diabetes Mellitus, Rural Community, Northern Nigeria, Blood Glucose, 
Non-Communicable Disease

\section{Introduction}

Diabetes mellitus (DM) is regarded as a chronic disease with high incidence, and it is also one of the conditions of public health importance. It was among the five significant global mortality risks [1]. According to the World Health Organization, one among ten adults had been diagnosed with DM [2]. Based on a report by the International Diabetes Federation in 2013, there were 3.9 million cases of diabetes in Nigeria, which was the highest prevalence rate in Africa [3]. It has also been shown that $80 \%$ of deaths by diabetes occur in low and middle-income countries, and by 2030, diabetes would record as the seventh leading cause of death [3].

Furthermore, studies have reported the prevalence of DM in urban centers like Lagos and Sokoto metropolis to be $7 \%$ and $4.6 \%$ respectively [4] [5]. A prevalence of $11 \%$ was also reported by another survey conducted in Lagos city [6]. A review conducted in 2017 reported the prevalence of DM in Nigeria was at $5.77 \%$ and that urban dwelling was identified to be a risk factor [7]. Thus, it has been suggested that DM could be classified as a disease for the high-income or urban dwellers [8] [9].

Majority of available studies conducted in rural areas have reported low level of prevalence of DM. A survey by Sabir et al. in a rural settlement in Northern Nigeria reported a prevalence of $0.8 \%$ [10]. A report by the Federal Ministry of Health and Social Services also reported prevalence rate as low as $0.65 \%$ in Mangu rural settlement, Northern Nigeria [6]. However, findings from a recent survey by Argu and Maduka in a rural community in Delta, Southern Nigeria, revealed that there was an $8.0 \%$ prevalence of DM in the community. Alcohol use, exercise, age, diastolic blood pressure and family history were identified as factors associated with the disease [9].

Tackling this emerging disease in Nigeria would require continuous monitoring and assessment. However, it has been reported that there is a paucity of research that assesses the burden of DM in Nigerian communities [8]. Hence, this study aimed to provide recent data about the prevalence of DM in a distant rural settlement in Northern Nigeria.

\section{Materials and Methods}

\subsection{Study Area}

The study was conducted in Tinda whose latitude and longitude is $10^{\circ} 47^{\prime} 14.23$ and $10^{\circ} 53^{\prime} 26.38$ respectively. Tinda is a rural community located in Dukku Local Government Area (LGA), Gombe State Nigeria. Majority of the locals were involved in farming, while other popular occupations were trading and animal husbandry. Gongola River flows via the west and north of the local government 
area. Dukku LGA is one of the 11 LGAs of Gombe State. The landmass of the LGA is $3815 \mathrm{~km}^{2}$, with a population of 207,190 , as at the last census. The dominant ethnic group present in the study area is Fulani.

\subsection{Sampling Design and Method}

The community-based study was cross-sectional in nature. The village consisted of around 200 adults, out of which 78 were purposively selected to participate in the survey. The sample size was estimated by using the sample size formula for cross-sectional surveys:

$$
n=Z_{\propto}^{2}(p-q) / d^{2}
$$

where $Z \alpha=$ A standard score at $95 \%$ confidence interval $=1.96$.

$P=$ prevalence of diabetes from a past survey in Northern Nigeria [15] $=$ 0.046 .

$q=1-p=0.954$

$d=$ degree of precision $=0.05$.

$n=$ sample size.

$$
n=\frac{1.96^{2} \times 0.046 \times 0.954}{0.05^{2}}
$$

$n=67.4$ adults.

Therefore, due to the small sample size a $15 \%$ non-response rate was included to increase the total sample size to 78 respondents.

The respondents were selected during a rural medical outreach organized by Living Stone Explorers; only respondents who met the inclusion criteria and consented to releasing their data were enrolled into the study.

\subsection{Inclusion/Exclusion Criteria}

- Residents under 18 years were excluded from the survey.

- Residents without autonomy or right to self-determination were excluded from the survey.

- Only residents that had dwelled in Tinda community since their childhood were included.

\subsection{Data Collection}

A health check-up service was provided by medical doctors, nurses, and medical laboratory scientists for three days in the village. The medical professional setup in a temporary out-patient clinic, where data was obtained from all the respondents. Basic socio-demographic data was obtained from each study participant and recorded appropriately. Fasting blood glucose level was measured using the WHO recommendations. Peripheral blood samples by finger puncture were collected early in the morning before participants took their breakfast. The Accu-Chek blood glucose meter was used with Accu-Chek test strips and microchips, with a lancet. Wet swabs were used to clean the thumb of the participants 
to disinfect and allowed them to dry. The glucometer was set, and a tests trip placed in the glucometer of the finger tip of thumbs of the participants, was pierced, and a little drop of blood was dropped on a piece that takes blood in by capillary action. The glucometer took a few moments to read, after which the results were displayed.

\subsection{Data Management and Analysis}

The data obtained from the study were entered and analyzed using the Statistical Package for Social Sciences (SPSS), version 20. Descriptive statistics were used to obtain frequency distribution tables, while independent t-test, and Analysis of Variance (one way-ANOVA) were used to derive associations between the participants' socio-demographic characteristics and the blood glucose level. The associations were derived at $95 \%$ confidence interval. The association between the respondent's glucose level and diastolic blood pressure was also derived by obtaining related community data from Olawade et al. [11].

The blood glucose level of the participants that were recorded and classified into three [12]:

Normal: less than $100 \mathrm{mg} / \mathrm{dl}(\leq 5.6 \mathrm{mmol} / \mathrm{L})$.

Pre-diabetes: $100 \mathrm{mg} / \mathrm{dl}-125 \mathrm{mg} / \mathrm{dl}$ (5.6 to $6.9 \mathrm{mmol} / \mathrm{L}$ ).

Diabetes: $>125 \mathrm{mg} / \mathrm{dl}(>6.9 \mathrm{mmol} / \mathrm{L})$.

\section{Results}

\subsection{Socio-Demographic Characteristics}

Of the 78 respondents selected to participate in this survey, less than half $(45 \%)$ of the respondents were female. Majority (69\%) of the respondents were between 18 to 35 years of age, while around $10 \%$ were over 50 years old. The oldest respondent was 90 years, while the youngest was 18 years. A dominant proportion (90\%) of the respondents was married. The weight of the respondents also ranged between $42 \mathrm{~kg}$ and $84 \mathrm{~kg}$. Majority (88\%) of the respondents were involved in agricultural related professions such as crop farming, animal husbandry and trading. The remainder was either unemployed or engaged in activities like tailoring and shoemaking.

\subsection{Respondents' Blood Glucose Level}

The mean blood glucose level of the respondents was $5.20 \pm 0.62 \mathrm{mmol} / \mathrm{L}$. The maximum reading recorded was $6.50 \mathrm{mmol} / \mathrm{L}$, while the lowest value recorded was $4.10 \mathrm{mmol} / \mathrm{L}$. Based on the American Diabetes Association classification (2017), 68\% of the respondents had normal blood glucose level, while $32 \%$ had blood glucose levels classified as pre-diabetes. None of the respondents had blood glucose level in the diabetes category. Therefore, the prevalence of diabetes was $0.0 \%$.

Categorizing the glucose levels of the respondents based on their age, half of the respondents over 50 years had their blood glucose level classified as pre-dia- 
betes, $31 \%$ of respondents between 36 to 50 years were classified as pre-diabetes, while about $30 \%$ of the respondents between 18 to 35 years also fell within this category. Figure 1 provides more details about this.

Categorizing their glucose level based on sex, a higher proportion (39.5\%) of male respondents had their blood glucose level in the pre-diabetes category compared to $22.9 \%$ of the female respondents. Figure 2 provides more information about this. Moreover, over one-third of both farmers (36\%) and traders (35\%) had their blood glucose levels classified as pre-diabetes, lower proportion of respondents' other job specifications had their blood glucose levels in the pre-diabetes category. Figure 3 provides more details about this.

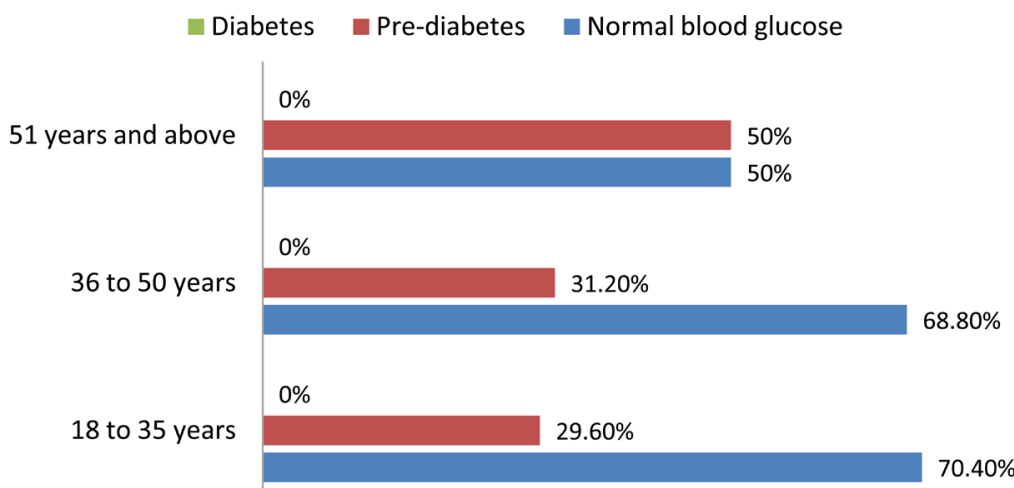

Figure 1. Blood glucose levels of the respondents based on their age categories.

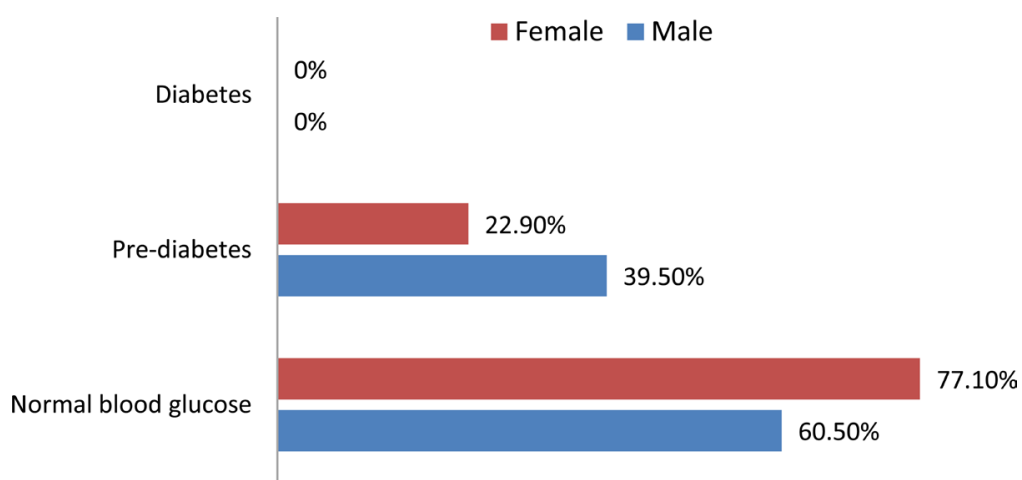

Figure 2. Blood glucose levels of respondents based on their sex.

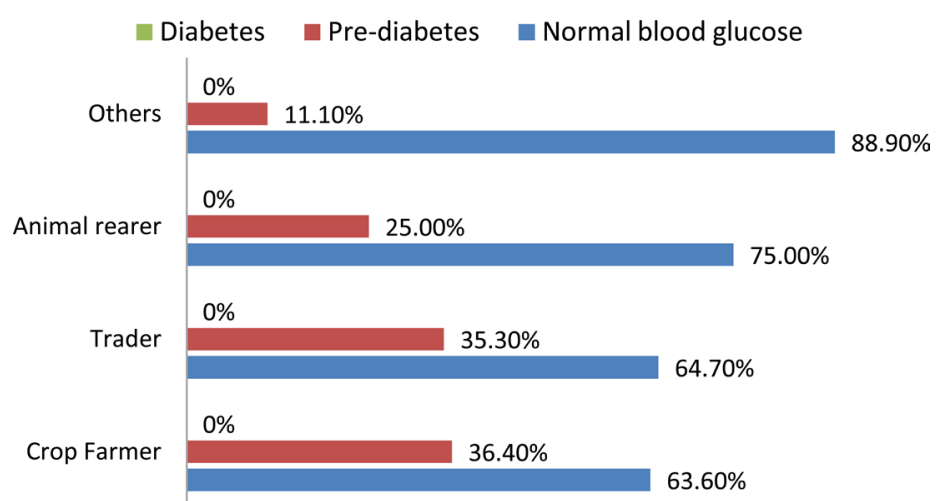

Figure 3. Blood glucose level of respondents based on their occupation. 


\subsection{Association between Respondents' Blood Glucose Levels and Socio-Demographic Characteristics}

There was no statistically significant association between the blood glucose levels of the respondents and their $\operatorname{sex}(\mathrm{p}=0.183)$. However, the male respondents had a higher average blood glucose level $(5.28 \pm 0.61 \mathrm{mmol} / \mathrm{L})$ compared to the female respondents $(5.09 \pm 0.63 \mathrm{mmol} / \mathrm{L})$. There was also no statistically significant association between the respondents' blood glucose level and their marital status $(\mathrm{p}=0.995)$. The married and single respondents had very similar average blood glucose levels $(5.20 \pm 0.62 \mathrm{mmol} / \mathrm{L}$ and $5.20 \pm 0.67 \mathrm{mmol} / \mathrm{L}$ respectively). Table 1 provides details about these associations.

Furthermore, there was no statistically significant association between the respondents' blood glucose levels and their age categories $(p=0.308)$. Respondents above 50 years had the highest average blood glucose $(5.44 \pm 0.73 \mathrm{mmol} / \mathrm{L})$, followed by respondents between 36 to 50 years with an average of $5.31 \pm 0.58$ $\mathrm{mmol} / \mathrm{L}$ ), while respondents between 18 to 35 years had the lowest average blood glucose $(5.13 \pm 0.62 \mathrm{mmol} / \mathrm{L})$. There was also no statistically significant relationship between the respondents' blood glucose level and their occupation ( $\mathrm{p}=$ $0.181)$. Traders had the highest average blood glucose level $(5.32 \pm 0.64 \mathrm{mmol} / \mathrm{L})$, followed by crop farmers $(5.24 \pm 0.61 \mathrm{mmol} / \mathrm{L})$, animal rearers $(5.14 \pm 0.68$ $\mathrm{mmol} / \mathrm{L}$ ) and then the respondents minority occupations such as tailoring and shoemaking had the least blood glucose level $(4.79 \pm 0.53 \mathrm{mmol} / \mathrm{L})$. Details of the associations are present in Table 2.

Table 1. Association between respondents' blood glucose level and their sex/marital status.

\begin{tabular}{|c|c|c|c|c|c|c|c|c|}
\hline \multirow{3}{*}{ Variables } & \multirow{3}{*}{ F } & \multirow{3}{*}{$\mathrm{T}$} & \multirow{3}{*}{ df } & \multirow{3}{*}{$P$-value } & \multicolumn{4}{|c|}{ t-test for Equality of Means } \\
\hline & & & & & \multirow{2}{*}{$\begin{array}{c}\text { Mean } \\
\text { Difference }\end{array}$} & \multirow{2}{*}{$\begin{array}{l}\text { Std. Error } \\
\text { Difference }\end{array}$} & \multicolumn{2}{|c|}{$\begin{array}{l}\text { 95\% Confidence } \\
\text { Interval }\end{array}$} \\
\hline & & & & & & & Lower & Upper \\
\hline Sex & 0.021 & 1.345 & 76 & 0.183 & 0.189 & 0.141 & -0.0910 & 0.470 \\
\hline Marital status & 0.209 & -0.006 & 76 & 0.995 & -0.00143 & 0.234 & -0.467 & 0.464 \\
\hline
\end{tabular}

Table 2. Association between respondents' blood glucose level and their age/occupation.

\begin{tabular}{cccccc}
\hline Variables & Sum of Squares & df & Mean square & P-value & F \\
\hline Age categories & & & & & \\
Between Groups & 0.92 & 2 & 0.461 & 0.308 & 1.197 \\
Within Groups & 28.85 & 75 & 0.385 & & \\
Total & 29.77 & 77 & & & \\
Occupation & & & & & \\
Between Groups & 1.89 & 3 & 0.629 & & \\
Within Groups & 27.88 & 74 & 0.377 & & \\
Total & 29.77 & 77 & & & \\
\hline
\end{tabular}




\subsection{Association between Respondents' Blood Glucose Levels and Their Blood Pressure}

There were no statistically significant association between the respondents' glucose levels and their diastolic $(\mathrm{p}=0.328)$ and systolic blood pressure $(\mathrm{p}=0.207)$. Respondents with normal blood glucose had a mean diastolic and systolic blood pressure of $85.0 \pm 20.7 \mathrm{mmHg}$ and $128.1 \pm 9.7 \mathrm{mmHg}$ respectively, while those with blood glucose levels in the pre-diabetes range had mean diastolic and systolic blood pressure of $80.3 \pm 17.0 \mathrm{mmHg}$ and $124.6 \pm 14.5 \mathrm{mmHg}$ respectively. Details of this association are provided in Table 3.

\section{Discussion}

The $0.0 \%$ prevalence of diabetes found in this study community is quite close to the prevalence of $0.8 \%$ obtained in a survey by Sabir et al. in a rural community in Northern Nigeria [10]. However, higher levels of prevalence have been reported in other Northern rural surveys. A survey among rural villages in Maiduguri reported a prevalence of $2.6 \%$ [13], while another survey conducted among rural communities in Kwara State revealed there was a prevalence of $2.9 \%$ [14]. In addition, studies conducted in rural communities in Southern $\mathrm{Ni}$ geria revealed relatively higher level of prevalence compared to the Northern communities. A survey conducted in a rural community in the Southern Nigeria reported a prevalence of $4.6 \%$ [15], while another survey in Delta state reported a prevalence of $8.0 \%$ [9].

The average blood glucose level of $5.20 \pm 0.62 \mathrm{mmol} / \mathrm{L}$ obtained in this survey is higher than the average blood glucose reported from rural surveys in Enugu $(4.64 \pm 1.7 \mathrm{mmol} / \mathrm{L})$, Kwara $(5.0 \pm 2.2 \mathrm{mmol} / \mathrm{L})$ and Sokoto $(5.0 \pm 0.60 \mathrm{mmol} / \mathrm{L})$ States [10] [14]. The higher average blood glucose among male respondents in this survey was also like results obtained in other rural surveys [10] [13]. Furthermore, surveys conducted in urban regions have reported prevalence rates as high as $10.5 \%, 11 \%$ and $24 \%$ [16] [17] [18].

The higher prevalence rates in urban areas have been associated with the

Table 3. Association between respondents' blood glucose level and their blood pressure (B.P).

\begin{tabular}{|c|c|c|c|c|c|}
\hline Variables & Sum of Squares & $\mathrm{df}$ & Mean square & $\mathrm{P}$-value & $\mathrm{F}$ \\
\hline \multicolumn{6}{|l|}{ Diastolic B.P } \\
\hline Between Groups & 372.06 & 1 & 372.06 & 0.328 & 0.968 \\
\hline Within Groups & $29,199.44$ & 76 & 384.20 & & \\
\hline Total & $297,571.50$ & 77 & & & \\
\hline \multicolumn{6}{|l|}{ Systolic B.P } \\
\hline Between Groups & 211.93 & 1 & 211.925 & 0.207 & 1.620 \\
\hline Within Groups & 9942.08 & 76 & 130.817 & & \\
\hline Total & $10,154.00$ & 77 & & & \\
\hline
\end{tabular}


predominance of sedentary lifestyle, and other factors like high-calorie diets, smoking and drinking [10]. The predominance of physically active occupations like crop farming and animal husbandry among the rural dwellers in this Tinda community could be a contributory factor to the zero prevalence of DM. Moreover, due to the remoteness of the village, common alcoholic beverages were not available for the residents. Also, palm wine trees commonly known to produce alcohol locally were not available in the study area due to the climatic conditions. This implies that the villagers did not have routine access to alcohol, which could also be a contributory factor to the zero-diabetes prevalence. It has been reported that rural areas that are beginning to report relatively higher prevalence of DM are most definitely embracing some of the associated urban lifestyles [9].

In addition, past studies have reported statistically significant association between DM and hypertension, thereby making DM a risk factor of hypertension [19] [20]. However, in this study there was no statistically significant association derived between glucose level and blood pressure. This is probably because none of the respondents had blood glucose levels in the diabetes range. This hypothesis was further strengthened as none of the blood glucose groups had high blood pressure. In conclusion, lack of basic health facilities in rural areas have been reported to hamper global targets to reduce the prevalence of non-communicable diseases [21]. With the paucity of health facilities in the study area, it becomes almost impossible for the locals to monitor their health, thereby making it difficult to track the trends of non-communicable diseases in such areas.

\section{Conclusion}

The lack of basic health services in this rural community implies that it would be difficult to continuously monitor the prevalence of non-communicable diseases like DM. Preventive health interventions via health promotion and education need to be facilitated in such rural communities so as to discourage rural dwellers from embracing some of the adverse lifestyle factors that could predispose them to DM.

\section{Limitation of the Study}

Blood glucose levels were evaluated just based on a single contact via random blood sugar. This was because the medical outreach was just for a couple of days. Moreover, due to the lack of health care facilities in the distant village, majority of the dwellers had not participated in routine health checkups, thereby lacking medical records. This made it difficult to account for factors like family history and other possibly undetected co-morbidities. Furthermore, because the village was small and sparsely populated, the sample size was also small. Lastly, due to the remoteness of the study location, it was difficult to link up with an Institutional Review Board. 


\section{Compliance with Ethical Standards}

The researchers were bound to the three ethical principles-beneficence, respect for human dignity, and justice through the survey. With the rural community lacking a health center, majority of the villagers had never undergone a health check. This survey was an opportunity to tell the world their story, with the hope that the data provided would influence policy makers. Verbal consent was obtained from the study participants before they were enrolled into the survey. Only autonomous adults (at least 18 years) were allowed to participate in the survey. No personal or identifiable information was collected from the participants; each respondent was assigned a study code. No undue compensation was given to the participants. All the villagers had equal access to medical care notwithstanding on whether they enrolled in the study or not. Due to the unavailability of a tertiary hospital around the village and the far distance between the village and the city, the research team was unable to obtain an IRB ethical approval.

\section{Acknowledgements}

We thank the leadership and members Living Stone Explorer International for their invaluable support.

\section{Conflicts of Interest}

The authors declare no conflicts of interest regarding the publication of this paper.

\section{References}

[1] World Health Organization (2009) Global Health Risks: Mortality and Burden of Disease Attributable to Selected Major Risks. WHO, Geneva.

[2] World Health Organization (2012) World Health Statistics: A Snapshot of Global Health. WHO, Geneva.

[3] International Diabetes Federation (2013) IDF Diabetes Atlas. 6th Edition. International Diabetes Federation.

[4] Olatunbosun, S.T., Ojo, P.O., Fineberg, N.S. and Bella A.F. (1998) Prevalence of Diabetes Mellitus and Impaired Glucose Tolerance in a Group of Urban Adults in Nigeria. Journal of the National Medical Association, 90, 293-301.

[5] Sabir, A.A., Isezuo, S.A. and Ohwovoriole, A.E. (2011) Dysglycaemia and Its Risk Factors in an Urban Fulani Population of Northern Nigeria. West African Journal of Medicine, 30, 325-330.

[6] Akinkugbe, O.O. (1997) Non-Communicable Diseases in Nigeria: National Survey (Final Report) on Hypertension, Coronary Heart Disease, Diabetes Mellitus, Haemoglobinopathies, G6PD Deficiency and Anaemia. National Expert Committee on Non-Communicable Diseases. Federal Ministry of Health and Social Services, Lagos.

[7] Uloko, A.E., Musa, B.M., Ramalan, M.A., Gezawa, I.D., Puepet, F.H., Uloko, A.T., Borodo, M.M. and Sada, K.B. (2018) Prevalence and Risk Factors for Diabetes Mellitus in Nigeria: A Systematic Review and Meta-Analysis. Diabetes Therapy. Re- 
search, Treatment and Education of Diabetes and Related Disorders, 9, 1307-1316. https://doi.org/10.1007/s13300-018-0441-1

[8] Tukur, D., Aliyu, A.A. and Shehu, A.U. (2016) A Review of Population-Based Studies on Diabetes Mellitus in Nigeria. Sub-Saharan African Journal of Medicine, 3, 59-64. https://doi.org/10.4103/2384-5147.184351

[9] Arugu, G.M. and Maduka, O. (2017) Risk Factors for Diabetes Mellitus among Adult Residents of a Rural District in Southern Nigeria: Implications for Prevention and Control. Nigerian Journal of Clinical Practice, 20, 1544-1549.

[10] Sabir, A., Ohwovoriole, A., Isezuo, S., Fasanmade, O., Abubakar, S. and Iwuala, S. (2013) Type 2 Diabetes Mellitus and Its Risk Factors among the Rural Fulanis of Northern Nigeria. Annals of African Medicine, 12, 217-222. https://doi.org/10.4103/1596-3519.122689

[11] Olawade, D.B., Wada, O.Z., Afolalu, T.D. and Barka, I.A. (2020) Evaluations of Hypertension among Adult Residents of Tinda Rural Community, Nigeria. International Journal of Public Health and Epidemiology Research, 6, 154-159.

[12] American Diabetes Association (2017) Classification and Diagnosis of Diabetes. Diabetes Care, 40, S11-S24. https://doi.org/10.2337/dc17-S005

[13] Okesina, A.B., Oparinde D.P., Akindoyin, K.A. and Erasmus, R.T. (1999) Prevalence of Some Risk Factors of Coronary Heart Disease in a Rural Nigerian Population. East African Medical Journal, 76, 212-216.

[14] Hendriks, M.E., Wit, F.W., Roos, M.T., Brewster, L.M., Akande, T.M., de Beer, I.H., et al. (2012) Hypertension in Sub-Saharan Africa: Cross-Sectional Surveys in Four Rural and Urban Communities. PLoS One, 7, e32638. https://doi.org/10.1371/journal.pone.0032638

[15] Isara, A.R. and Okundia, P.O. (2015) The Burden of Hypertension and Diabetes Mellitus in Rural Communities in Southern Nigeria. The Pan African Medical Journal, 20, 103. https://doi.org/10.11604/pamj.2015.20.103.5619

[16] Ekpenyong, C.E., Akpan, U.P. and Ibu, J.O. (2012) Gender and Age Specific Prevalence and Associated Risk Factors of Type 2 Diabetes Mellitus in Uyo Metropolis, South Eastern Nigeria. Diabetologia Croatica, 41, 17-28.

[17] Ige, O.K., Owoaje, E.T. and Adebiyi, O.A. (2013) Non Communicable Disease and Risky Behaviour in an Urban University Community Nigeria. African Health Sciences, 13, 62-67. https://doi.org/10.4314/ahs.v13i1.9

[18] Nwafor, A. and Owhoji, A. (2001) Prevalence of Diabetes Mellitus among Nigerians in Port Harcourt Correlates with Socio-Economic Status. Journal of Applied Sciences and Environmental Management, 5, 75-77. https://doi.org/10.4314/jasem.v5i1.54950

[19] Unadike, B.C., Eregie, A. and Ohwovoriole, A.E. (2011) Prevalence of Hypertension amongst Persons with Diabetes Mellitus in Benin City, Nigeria. Nigerian Journal of Clinical Practice, 14, 300-302. https://doi.org/10.4103/1119-3077.86772

[20] Onuoha, F.M. and Egwim, J.I. (2017) Hypertension amongst the Diabetic Patients Assessing Care in A Primary Care Setting in South-Eastern, Nigeria. Journal of Diabetes and Clinical Studies, 1, 001-006.

[21] Wada, O.Z., Olawade, D.B., Afolalu, T.D., Oluwatofarati, A.O. and Akinwalere, I.G. (2020) Prevalence of Hypertension among Rural Adults and Availability of Management Services in Abimbola Community, Ayedaade Local Government Area, Osun State, Nigeria. Journal of Hypertension and Management, 6, 046.

https://doi.org/10.23937/2474-3690/1510046 